\title{
1. Putting Citizens First: Engagement in policy and service delivery for the 21st century
}

\author{
Evert Lindquist
}

During the late 2000s the theme of 'citizen-oriented government' steadily rose to the top of the public management agenda (OECD 2009). Governments at all levels have declared their interest in finding better ways to respond to and serve citizens and communities through better-designed programs and consultative processes (Advisory Group on the Reform of Australian Government Administration 2010; Bourgon 2011). For many, the theme of 'putting citizens first' is a natural extension of the new public management (NPM) initiatives, which sought to better serve citizens as clients and customers, leading to experimentation and institutionalisation of integrated service delivery and innovations such as Centrelink in Australia, Service Canada (Halligan and Wells 2008; Dutil et al. 2010) and the Common Measurement Tool in Canada, and New Zealand's Kiwi Counts. For others there are resonances with whole-of-government, joinedup government, and horizontal governance themes (Management Advisory Committee 2004), motivated by outside-looking-in perspectives.

Many observers point out that democratic governance has always been about better serving and engaging citizens, and that institutional reforms, which are informed by the advent of new technologies, can be traced back a hundred years and more. Despite the considerable experimentation and progress made by many governments over the last decade, the expectations about better connecting governments to citizens have increased. Elected leaders and officials are keen to lessen the distrust of citizens in government and build constructive support through better policy and higher quality services. Governments at all levels in Australia and New Zealand have been taking greater interest in measuring citizen satisfaction, and finding ways to work with citizens and communities to design services. Moreover, citizens and governments continue to see new possibilities in web-based technologies deriving from private sector innovation, and governments are under pressure to increase the value-for-money obtained from programs in increasingly tight fiscal environments. Most recently, the ambition of inculcating a citizen orientation when delivering services and designing policy animated Western Australia's Economic Audit Committee's Putting the Public First: Partnering with the community and business to deliver outcomes (October 2009) and the Commonwealth's Ahead of the Game: Blueprint for the reform of Australian Government administration (March 2010). 
The themes of 'citizen-centred' or 'citizen-focused' government and governance have ever greater resonance because of the expanding opportunities presented by digital information and communications technology (ICT) (Borins et al. 2007; Roy 2008). It is now conceivable to think not only of citizen-oriented service and improved policy delivery, but genuinely citizen-informed and even citizen-designed and often specifically tailored interventions that are designed to accommodate the needs of individuals and communities - what some refer to as the 'individualisation' of policy and service delivery (Howard 2010). Such developments are consistent with the 'public value' perspective which calls on political leaders and public sector executives to explore myriad ways to provide services for citizens and communities (Moore 1995; Alford and O'Flynn 2009, 2012). Advocates for Government 2.0 and Open Government suggest that ICTs might drive governments to dramatically re-conceive the role of the public bureaucracies in delivering programs and designing policy (Dunleavy et al 2006; Government 2.0 Task Force 2009). Still others have referred to this as the 'service state' (Dutil et al. 2010; Wanna et al. 2010).

The theme of the Australia and New Zealand School of Government's (ANZSOG) 2011 annual conference in Sydney, 'Putting Citizens First' was designed to explore these ideas. Early in the planning process, the program committee ${ }^{1}$ recognised that the phrase 'citizen-oriented' government or governance can mean different things to different people, and even committed practitioners and scholars can talk past each other when discussing how to better design, serve and work with citizens. Accordingly the conference was organized around four broad areas:

- Integrating services for citizens: searching for better ways to integrate the services that governments provide with the specific needs of different categories of citizens, clients or customers in mind, and offering readily accessible information on those services.

- Discovering citizen needs and preferences: systematically learning more about the experience of citizens in receiving the services delivered to them, and using that feedback to improve the delivery of those programs.

- Engaging citizens in policy and service design: improving how governments engage citizens in the design of policy and service delivery regimes, sometimes involving co-design and co-re-design of services and programs, and sometimes co-production.

\footnotetext{
1 The author sat on the 2011 ANZSOG annual conference steering committee. Beyond developing the program, however, it was the rest of the committee - Tracey Fisher, Peter Allen, Glen Sheldon, John Wanna, and many others - who did the heavy lifting in identifying and contacting speakers, organising logistics, and making the conference run smoothly. Sam Vincent did yeoman's work with speakers to develop the papers and reflections comprising this volume.
} 
- Improving public sector capability: developing strategies to improve capacity and capabilities in government in order to make progress on all three of the above fronts.

These areas are distinct but often overlap. All have been energised by the possibilities afforded by tested and emerging ICTs.

The general goal of the conference was to take stock of the state of practice and recent innovation in serving and engaging citizens at the local, state and national levels in Australia and New Zealand. This progress was to be put in context by getting a sense of international practice and contemporary academic perspectives on citizen service delivery and engagement. Speakers were asked to share their experiences, and identify barriers and issues as well as practical, effective and value-added strategies for moving toward citizen-oriented government. Speakers and conference participants were asked to identify areas where governments and officials might better serve citizens with breakthrough reforms, particularly taking advantage of new technology.

While the conference themes - service integration, eliciting citizen feedback, engagement, and capacity - were not new, we identified several broad questions to ask of presenters about the state of the art, where governments had made the most progress, and where the potential was for making further progress:

- How much progress had governments made with respect to promoting integrated service delivery, working within and across governments, and what are the prospects for doing even more?

- How much progress had governments made with respect to obtaining citizen feedback on services they deliver, and are they making second-generation efforts to discovering citizen needs and preferences?

- How much progress had governments made with respect to engaging citizens and communities in service delivery and policy design matters, and can governments go further with respect to co-designing and co-delivering services?

- What needs to be done to build the culture, repertoires, and sensibilities in public sector organisations to respond to and anticipate demands for better services and engagement, and take advantage of technological possibilities which promise to put citizens first?

We invited keynote speakers who could offer conceptual but grounded perspectives on these questions as well as an impressive number of practitioners who could share recent experience on implementing citizen-oriented service delivery, measurement, and engagement strategies. 
Several questions arise because of inherent tensions in our governance systems and different ideas of how to respond to citizen needs and interests. These include:

- Are Westminster governance systems, with their vertical accountabilities and divided responsibilities, necessarily incongruent with a citizen orientation, or can they be made to move faster and further?

- Can governments increase the trust of citizens in government by improving services and better engaging them, or will citizens continue to disengage from government no matter how much progress is made?

- How can citizen input be meshed with the input that inevitably comes from experts, stakeholders, and government agencies (often other levels of government)?

- Do governments provide what citizens and communities want or need, or do they focus on better providing services that governments have identified in certain ways?

- Is co-production the same thing as engaging citizens and deliberative democracy? If not, how does it differ, and how and when can they complement each other?

None of these tensions are new or deal-breakers for making headway. Indeed, the goal of the conference was to recognise and assess new possibilities for making progress: there are new technologies, two new generations of public servants and citizens taking on leadership roles as the post-World War II baby-boomers exit the stage, and no shortage of recent innovations to serve as exemplars and encouragement. This is a critical time to consider how to build capacity and make strategic investments focused on better working with and responding to citizens.

The conference was a success with 450 participants and 32 speakers, who were invited from Australia, New Zealand, Canada, Singapore, the United Kingdom, and the United States to provide diverse perspectives from different levels of government and sectors on strategies and experiences for putting citizens first. We designed the workshop sessions so that panellists spoke briefly to their cases studies of innovation in order to elicit dialogue with the audience about their own experiences.

This collection of essays, based on the presentations made at the conference, seeks to capture many of these insights. ${ }^{2}$ The papers generally track the flow of the conference, although some have been re-grouped with others that cover similar ground. This volume is organised into five parts:

2 For another set of reflections, see Andrew Podger (2012). 
Setting the Scene: The evolving landscape for citizen engagement

Drivers for Change: Innovations in citizen-centric governance

Case Studies: Land management and Indigenous empowerment

Case Studies: Fostering community engagement and connectedness

Case Studies: Engaging with information technology and new media

This chapter provides an overview of the themes and arguments of the volume and, in a sixth section, provides an assessment of where progress has been made in the citizen-oriented governance agenda, and identifies avenues for further dialogue and research.

\section{Setting the scene: The evolving landscape for citizen engagement}

Before delving into the drivers and approaches for canvassing and engaging citizens, the steering committee sought to provide perspective on the context in which putting citizens has been proceeding. We felt this was necessary because, as indeed many speakers noted, many of the motivations and aspiration behind more citizen-centred governance and government are not new - arguably, strands of these ideas have been at play for close to two decades. Even if progress has been made, and new possibilities are at hand, the strong interest in developing more of a citizen orientation connotes some impatience and urgency, implying inertia and possibly government resistance to these ideas. If the initiatives represented in this volume constitute the next wave of reform, do realistic strategies and expectations exist for dealing with the broader dynamics and tensions for better engaging and responding to citizens? Three speakers from outside Australia and New Zealand were invited to provide international and theoretical perspectives on these issues.

The conference began with a provocative question: can Westminster practice and reflexes, and the agendas of duly-elected governments, co-exist with efforts to improve service delivery and engage citizens or are they in considerable tension, as argued by Jeffrey Roy (2008)? In Chapter 2, Gerry Stoker argues that a more fundamental normative tension is at play about engaging citizens in Westminster and other systems: he contrasts an elite, party-driven 'protective approach' limiting government engagement to a 'developmental approach' which sees democracy and participation as fundamental values, leading to greater commitment to citizen engagement. Each, he argues, has their own weakness: the protective model resists change, the developmental model 
risks utopianism. Both proceed against a general climate of 'anti-politics' and lack of trust in governments and democracy in OECD countries, which leads to disengagement, blended with media saturation, high expectations of government, and the decline of traditional parties. Nevertheless, Stoker sees great potential to increase engagement, but governments must recognise citizens and communities have differing intensities of preference for engagement, and this requires understanding the motivators and inhibitors to engagement. $\mathrm{He}$ outlines a framework for systematically building capacity, involving citizens and groups as part of a broader civic infrastructure and multiple instruments which can be deployed depending on the type of citizen and community, and through 'nudges' (Stoker, 2011). Stoker suggests that, while governments need to take democracy seriously, they should resist catering to populist impulses, and manage expectations about the value that citizen engagement can add to policy and service design.

The possibilities for better engaging citizens has generated interest by governments around the world, which are simultaneously struggling with the implications for governing. Don Kettl took on the question 'Facilitating choice, letting go: are governments really willing to let citizens and communities determine policy choices and service mixes?' In Chapter 3, Kettl provides an interesting historical view rooted in recent US experience, but, like Stoker, also sees more fundamental forces at play. He depicts the NPM wave of reforms in the United States during the 1990s and beyond as essentially about better engaging and responding to citizens, along with being more efficient and accountable. He suggests that this wave of reform is a spent force in the United States, not to be succeeded by promising debates over the possibilities of co-production and responsive service delivery for citizens, but rather, by an uneasy and far more fundamental debate about the role of government in a resource-strapped environment. While considerable devolution and deregulation has occurred, he points to inconsistent public expectations of government. Even his more optimistic wonderment about the possibilities flowing from the open data movement to respond to citizen and community needs (Rat Rub-out Baltimore), ${ }^{3}$ to show where services are distributed across the United States at different levels of aggregation, or to put community interventions and accountability on a different and more comprehensive footing, is chastened. He worries that citizens and communities simply might not care or be interested as they seek ever lower taxes and distrust government. Like Stoker, Kettl believes it will be important for governments to work hard to show that it is listening (and responding) to citizen needs.

3 Adam Bednar, 'Charles Village Rat Rub-out Produces Results', North Baltimore Patch (September 28, 2011) at http://northbaltimore.patch.com/articles/charles-village-rat-rub-out-produces-results 
Animating government investments in improving service delivery was a hope that better service might lead to increased citizen trust in government (e.g., Heintzman \& Marson 2005; Halligan \& Wells 2008), but, as Stoker and Kettl note, citizens seem even more disconnected from their governments. Even if governments continue to make progress with citizen-oriented service delivery and engagement, will trust and satisfaction in government rebound, or will the gap continue to widen? In his keynote address, Rolf Alter of the Organisation for Economic Co-operation and Developments (OECD) addressed the topic of 'Citizens and governments: are they more connected or more disconnected?' In Chapter 4, Alter provides insights informed by several OECD studies and reports carried out over the last decade (OECD 2001, 2009 and 2011). He observes that during the 2000s, and since a succession of significant reports, the OECD has focused on citizens with respect to engaging on policy, open data and government. On the one hand, the interest of governments has emerged from genuine interest in citizen rights and expectations about engagement by their governments and the hope that more engagement might lead increased trust of government, but the real challenge for OECD leaders is how to engage in useful, productive, and cost-effective ways with sufficient information. Alter points out that exploring and taking advantage of the promise of social media and other digital technology will require new capacity and repertoires in government (see Chapter 9, this volume). He wonders whether the ability of citizens to organise and move faster than governments in response to political and other events through social media (some communities better than others), will outstrip government's other efforts to more evenly and systematically engage citizens, communities, and civil society organisations.

\section{Drivers for change: Innovations in citizen- centric governance}

Several speakers - internationally recognised innovators and thinkers in their respective areas - were invited to explore different approaches, techniques and frameworks for engaging citizens (Christian Bason, John Alford, Bette-Jo Hughes, Lynelle Briggs, and Martin Stewart-Weeks). ${ }^{4}$

Bason of Denmark's MindLab addressed the question of 'Engaging citizens on policy and service design: can this be meshed with input from experts, stakeholders and other governments?' Governments often engage citizens

4 The conference did not review the many different and emerging approaches for engaging citizens in consultation and deliberation. The focus was more on how diverse experts might assist in helping government to better understand citizen needs, as opposed to exploring how citizens, experts and stakeholders might better interact with each other in broader consultation and deliberative processes, and how governments can better balance these inputs. 
and experts sequentially, but, in Chapter 5, Bason describes how they can be fused to more fully understand the experience of citizens and, in turn, design better policies and services that can lead to threshold increases in the quality of outcomes. He argues that significant rethinking of public services is required due to a 'perfect storm' of relentless change, the demographic rollover, the innovative nature and declining costs of technology, and the increasing expectations of citizens about the quality and fit of services. He describes how different research and design processes of MindLab are calibrated to understand challenges and incubate new ways to deliver services, all proceeding with the goal of 'co-creating' policy and public services with those who will use them. Bason reviewed examples of how MindLab staff ask or draw out individuals about their experiences in trying to access and use a service, and work with them to identify whether it could be delivered better - this means that members of the research team often need to put themselves in the shoes of clients and undertake systematic and creative enquiry to gain insight and to challenge assumptions (Bason 2010). This requires engaging citizens in new ways, using a variety of techniques (not just surveys, but qualitative information and other approaches such as film, ethnography, art, visual tools, role-playing and mapping). Bason and his colleagues seek to engage not only a wide circle of users but also a broad circle of experts and other professionals who look at problems differently. As we will see later, this engagement and design sensibility has informed recent practice in the Australian and New Zealand governments.

Alford offers a broad framework for understanding how public services are already co-produced with citizens and clients, an important perspective to have in mind before considering how to innovate. He tapped his award-winning research (Alford 2009) to address the topic of 'engaging citizens in co-producing service outcomes'. Alford's insight is that when considering how services are provided to citizens, whether directly by governments or other entities, citizens are usually involved in varying degrees in co-producing those services through diverse contributions (for example, by filling out forms or making requests), and this may be done for material or non-material reasons. Alford's perspective goes beyond the citizen and ostensible deliverer to encompass the whole chain of upstream and downstream contributors, who create conditions or enable services to occur. His argument is that, before considering designing policy or new services (what we could call co-creation or co-design), one should appreciate the extent of co-production already relied upon. In his view, co-creation and coproduction should not be about getting citizens to shoulder more of the costs of service delivery, but rather to understand that co-production works under certain circumstances, with a mix of motivations and interdependency. As for Briggs (Chapter 6), he points out this mix and balance varies significantly across beneficiaries, obligators or regulators, and volunteers, depending on the service. 
Engaging citizens in research and design is only the latest effort to better understand how citizens experience the delivery of services. Hughes from the British Columbia Public Service and representing Canada's Institute for CitizenCentred Service Delivery, canvasses the evolution of efforts to obtain feedback from citizens and measure attributes of service delivery, which resulted in a collaborative cross-government centre-of-excellence. In Chapter 5, Hughes addresses the topic 'Measuring citizen feedback: what is citizen satisfaction? What is the state of the art?' She reviews the origins of the Citizens First movement, the interest in understanding the drivers of customer satisfaction with public services, the development of the Citizens First methodology and the Common Measurement Tool, and the establishment of the institute to further the idea of measuring the quality of service across governments within and across national boundaries (Dinsdale and Marson 1999; Schmidt \& Strickland 1998a, 1998b; Marson \& Heintzman 2009). Consistent with the themes of the Putting Citizens First conference, there has been growing interest by Canadian governments in complementing these measurement tools with qualitative approaches for involving citizens in a conversation about the kind and mix of services and policy they or their communities would like to receive (Howard 2010). Hughes also notes that the BC Government has recently announced its policy on open data and government, informed by the previous work of Australia and New Zealand governments.

In Chapter 6, Briggs shifts gears, moving from considering citizen engagement and the re-design of specific policy and services to merging and re-orienting bureaucracies in order to provide more integrated and better tailored services. As then head of Medicare Australia, Briggs was part of the leadership team merging three organisations - Medicare Australia, Centrelink, and Department of Human Services - to better integrate service delivery and policy interventions for health services, income support and child support. In her words the goal is to 'truly put people at the centre of everything we do'. This is a significant task involving structural, technological, and cultural change, involving a total of 40,000 staff, 550 offices, and 170 programs. Briggs describes how, along with new technology and diverse delivery channels, the emerging organisation is seeking to establish new ways of listening to and working with client, customer, citizen, and communities by means of community forums with staff and other techniques such as building citizen pathways (see Chapter 13) in order to better understand needs and tailor service mixes. Briggs observes that public agencies must be well organised, focused, and culturally disposed in order to properly engage citizens and their communities on an ongoing basis, which also requires sustained and visionary leadership.

Stewart-Weeks addresses the topic of 'Citizens, government and technology: what are the unrealised and emerging possibilities?' In Chapter 9, he briefly 
outlines how governments are starting to reshape conversations with citizens using social media, and how this process is not only growing, but, as Alter notes, is often driven from outside government, not from within it. Referring to Jocelyn Bourgon's New Synthesis project (Bourgon 2011), Stewart-Weeks notes that increased connectivity is not the same as greater connectedness and a culture of openness, sharing and co-creating. For government this implies 'having richer and more meaningful conversations with citizens who are increasingly learning to live in the world of pull and are increasingly frustrated by the world of push', where governments send information to be consumed by citizens rather than discussed. Stewart-Weeks identifies examples of government turning to Twitter, using videos to spark community dialogue, relying on Facebook as part of emergency responses, to elicit innovative ideas in concerted ways. He argues that private sector and public sector organisations are realising that citizens and external networks often know more than they do, and can respond faster. The trick is to recognise and embrace this dynamic, adopting new ways to monitor and tap that information and knowledge, and supplying data for citizen use in ways which might surprise government leaders, while not relinquishing 'old' means of engagement that are useful for certain purposes. Stewart-Weeks labels entities making this shift as 'edge organisations' with 'a fundamentally different power topology from traditional organisations', prepared to have 'bouncy' dialogues with citizens containing seeds for innovation and increased productivity. He argues making this shift will be essential in the future, where experimentation and emergence will become bigger facets of how governments, citizens and communities create public value.

Many of the themes explored in these presentations were taken up in the workshop sessions, which probed more specific cases. What follows provides summaries of these cases in three sections: land management and Indigenous empowerment; fostering community engagement and connectedness; and engaging with information technology and new media. Section 6 steps back to consider where progress has been made for putting citizens first, and where it has not, the implications for building capacity and strategic awareness in public service organisations, and issues which need to be taken up in further detail.

\section{Case studies: Land management and Indigenous empowerment}

This section introduces several cases on working with local organisations to manage land resources or increase the capacity of Indigenous communities, or both. We begin with three initiatives that rely on networks to deal with, 
respectively, remediating degraded farm land in Victoria, state reserves in New South Wales, and Indigenous landholders in the Kimberley, and then consider three diverse perspectives on empowering Indigenous communities.

Australia, of course, has vast territories which need to be managed and the issues that managing this land raises are often beyond the scope of traditional government service delivery. Three cases explore some interesting approaches:

- Jenny Pequignot (Chapter 10) describes how a coalition of farmers in northwestern Victoria, collaboratively addressing land degradation issues, became a much larger network of entities now called Landcare. Initiated in the late 1980s, Landcare is now a collective of community-based and volunteer natural resource management groups. It relies on local citizens to tackle issues, lever other resources and networks, and requires limited government support. Pequignot observes that government representatives regularly engage and listen, essentially working as a junior partner in the relationship and resisting treating the network as a government delivery arm.

- Peter Houghton (Chapter 11) reviews how New South Wales manages its land reserves by means of community trust boards and volunteers. Houghton reviews how caravan park operators and the Crown Lands Division partnered to create the Caravan and Camping NSW website to improve quality and use of facilities, which is also a vehicle for accountability.

- Mark Chmielewski (Chapter 12) chronicles the origins of the Indigenous Landholders Service and the entrepreneurial leadership and dialogue with communities, along with collaborative and multi-faceted long-term solutions, that are now hallmarks of the service

Chapter 13 provides other perspectives exploring how to strengthen engagement and empower Indigenous Australians. Adrienne Gillam of the Department of Families, Housing, Community Services and Indigenous Affairs describes how, the impetus of the Remote Service Delivery National Partnership was dedicated to 'closing the gap' by introducing a different way of working with Indigenous communities. The second example in the chapter is a case explored by Ian Mackie of Queensland's Department of Education and Training. The department champions distinct, targeted and collaborative strategies for improving achievement in education achievement. His colleague, Michael Hansen, Principal of Cairns West State School, amplifies these points, observing that principals are critical because they can develop incentives, and work with parents and teachers, to improve student attendance and achievement. 
Putting Citizens First

\section{Case studies: Fostering community engagement and connectedness}

Although there can be no fast distinctions, the case studies in this section provide examples of social policy interventions relying on engagement with citizens, communities and networks to achieve goals and often tailored approaches. The cases have been arrayed to move from higher to lower levels of analysis: national, state, organisational, and on the ground.

Ang Bee Lian (Chapter 14) describes how Singapore's social safety net and human service provisions have promoted self-reliance, with family as the first line of support and considered the basic building block of society. She describes how the government has sought to more proactively work with a 'many helping hands' approach by developing partnerships among government agencies, private and community agencies, business and educational institutions, socialcultural and religious organisations in order to increase social inclusion and social capital, and often requiring experimentation and innovation.

Yehudi Blacher (Chapter 15), former chief executive for the Victorian Government, describes the 10-year process of merging planning and community development in the state of Victoria to develop stronger and more resilient communities. A key lesson here is that a broad goal of understanding the state of cohesion and services in communities across the state requires sustained and often creative effort, working within and across levels of government.

Shane Chisholm (Chapter 16) describes how Housing New Zealand (HNZC) has engaged in a multi-year, top-to-bottom organisational transformation process since 2009, which has focused on better serving customers. Chisholm notes that reporting and actively seeking data and feedback of all kinds met resistance early on, but has become more accepted and part of the organisational culture.

Chapter 17 provides three different examples of organisations seeking to improve how they secure customer feedback.

- James Mowat describes how Land Information New Zealand (LINZ) underwent a profound shift since 2004 to move from a statutory-driven to more a consultative, strategic and efficient approach with the regulated stakeholder community. This process was informed by internal reviews, stakeholder expert committees and other forms of feedback, as well as sustained executive leadership.

- Jim Scully of ThinkPlace NZ reviews the approach that his firm takes when working with clients seeking to engage citizens. Scully stresses the need to 
understand customer pathways, both with respect to the trajectory of their own circumstances and obtaining services from client organizations.

- David Sweeny, Director of Co Design Practice with the Commonwealth Department of Human Services, has drawn on the MindLab approach to undertake exploratory research with client groups, and mapped and developed visualisations of the experiences they have, as part of a service delivery reform initiative (see Briggs, Chapter 7).

The two cases in Chapter 18 focus more directly on ways to engage citizens and communities:

- Nicole Pietrucha of Medicare Australia's Community Engagement Branch provides a community-level view of their re-design process and how to build co-design capability.

- Jo Sammut of the NSW Department of Family and Community Services describes how the Building Stronger Communities (BSC) initiative was implemented in the Sydney suburb of Macquarie Fields.

In Chapter 19, Deb Symons the former head of the Victorian Bushfire Recovery and Reconstruction Authority's community engagement team, provides insights into how her team worked with devastated communities to shape the rebuilding process. Symons notes that strong executive leadership backing is required for the approach that was taken by her team to succeed, and front-line managers and staff require excellent facilitation, negotiation, and arbitration skills.

\section{Case studies: Engaging with information technology and new media}

Several workshop sessions had case studies which focused on the use of new information and social media technologies in different contexts. These are presented here as a complement to the Rat Rub-out case mentioned by Kettl (Chapter 4) describing the tools used in very different contexts, the Queensland emergencies and consultation processes by the New Zealand Inland Tax Revenue for tax legislation.

In Chapter 20, Fiona Rafter of Queensland's Department of Community Safety, reminds us of the tremendous number of emergencies and disasters which wrecked havoc on Queensland during late 2010 and early 2011. Her paper observes that managing the contribution of volunteers requires investments of time, training, others cost, recognition, and people management and she points out that government leaders have to recognise how bureaucratic culture and incongruent recruitment and other policies might create barriers for recruiting and retaining volunteers. 
Mary Craig, Deputy Commissioner of Inland Revenue New Zealand's Corporate Services, describes in Chapter 21 how her organisation has been experimenting with online forums to engage a wider range of citizens about tax policy than with traditional consultation processes. Craig concludes that this experience has caused IRNZ to look at consultation differently, take risks, and continue to explore how to use different media to engage with citizens. Chapter 22, by Gail Kelly of IRNZ's Research Corporate Strategy group provides more detail on the experimentation engaged in by the service.

\section{Putting citizens first: What has been accomplished and learned?}

An overarching goal of the 2011 ANZSOG conference was to take stock of progress towards integrated service delivery, measuring citizen satisfaction, and encouraging citizen engagement and co-production, and to identify where further progress could be made. Another goal was to ascertain what capabilities and capacities were needed inside government to continue making progress in the 'putting citizens first' agenda. This section addresses the questions animating the conference and also provides several insights about capability.

\section{How much progress has been made on integrated service delivery, working within and across governments?}

It is difficult to arrive at any other conclusion than governments are trying to make progress on integrated service delivery models, but this work proceeds at different levels of analysis. So, for example, not only has the Commonwealth Government continued with its Centrelink model, but it has expanded it to include Medicare Australia and the Department of Human Services. Such integration clearly involves backroom and front-room elements, with the latter certainly focused not simply on government-redesigned service delivery, but, more expansively, on including citizens and communities. Also represented are examples from New Zealand Housing Corporation which has been transforming its culture, systems, and repertoires for engagement around its customer promise. Undoubtedly there are more examples from different departments and agencies in Australia and New Zealand at the national, state, and local levels. It also seems clear that governments are proceeding with integration only with certain clusters of service that are delivered either by the same or cognate organisations associated with a given level of government. 
There are examples of Commonwealth and state initiatives engaging communities along with other government, business and non-profit organisations to develop partnerships. If the cases at the conference are in anyway representative, however, integrated service-delivery initiatives tend to be driven by one level of government, and other organisations are likely to be invited to participate during the implementation phase.

In short, there has been far less progress working across levels of government to present an integrated face and experience to citizens. This may constitute the next generation of service-delivery for governments, once they are ready, or citizens demand that it start happening.

\section{How much progress has been made in obtaining citizen feedback on services and shaping new citizen- oriented service mixes?}

Many Australian and New Zealand departments and agencies are aware of the Citizens First initiative and the measurement tools developed by the Institute for Citizen Centred Service Delivery. New Zealand introduced its own variation on the Citizens First methodology with Kiwi Counts, and other agencies have adopted similar approaches to measuring feedback through surveys of citizens and clients. The Victorian Government has systematically required local communities to measure citizen satisfaction and preferences on a wide variety of services, thereby providing broader and more integrated perspectives on the health and connectedness of those communities. The key drivers for making sense of progress continue to be regular reporting and accountability.

One element of Cosmo Howard's (2010) critique of Citizens First-type methodology is that customer satisfaction surveys might only focus on services that governments had chosen to deliver, the manner in which they had chosen to deliver them, and using criteria and a measurement tool that, while informed by citizen surveys, might not reflect the questions and issues citizens might raise in the context of particular services. He calls for more engagement with citizens to learn about what mix and channels of service they would provide and, where possible, to ascertain if they could be tailored for the specific needs of citizens and communities. As this volume demonstrates, many governments and public service leaders have turned that corner, embracing a more fulsome mix of methods for securing feedback and advice from citizens and communities.

The audience greatly appreciated Bason's keynote address at the conference, but many departments and agencies in Australia and New Zealand were already familiar with and been inspired by MindLab's innovative approaches (Bason 2010). Much of the MindLab approach draws on the practice of architecture 
and urban planning firms of hosting 'charrettes' to intensively work on designs and prototypes with experts and stakeholders, but also folds in other means for understanding the lives and needs of citizens. Clearly, consulting practices like ThinkPlace NZ are starting to fill this niche in this hemisphere. Even when some of the cases examined in this volume did not specifically seek to rely on such techniques, extended engagement and dialogue were intended to develop a citizen-based view of needs, priorities, and service mixes. If governments did not have such capacity to undertake such work, they were contracting for it and, in some cases, steadily building internal capabilities in this regard.

\section{How much progress has been made in engaging and co-designing with citizens and communities in service delivery and policy design matters?}

The papers in this volume suggest that vanguard departments and agencies have been adopting new approaches to engaging citizens with respect to service delivery, and in some cases bringing a wider circle of internal and external experts into the conversation about needs and design. There are examples of specific agencies transforming themselves, or building new units and capabilities to engage and work with citizens and communities. In many cases, the process was about trust-building, the sharing of information, and developing shared views and representations of existing patterns in service delivery and, in a few cases, new directions and partnerships.

For many contributors, however, the ultimate goal would be to have governments co-designing policy and service delivery regimes with citizens. The evidence does not suggest that there has been any significant movement towards 'macro' co-design of policy and service-delivery regimes in Australia and New Zealand. Nor should we expect Westminster systems to easily make such a change; governments find it difficult to co-design with each other, let alone with citizens. That said, important innovations can emerge from more circumscribed co-design arrangements on a local or national level.

Government representatives at the Putting Citizens First conference appreciated that engaging citizens and communities can no longer simply be about surveys, customer feedback, or a few visits. Rather, to be effective, citizen engagement requires making strategic investments over time, choosing the right kind of representatives and support, and steadily building trust over long periods of time. It is serious business, which has to be undertaken well, and yet, despite the need to ensure regular reporting and indicators of progress for those involved, it is often difficult to definitively show the effectiveness of such initiatives with respect to more effective programs, efficiency or lower costs. More importantly, 
it is widely recognised that more systematically engaging citizens requires new capabilities and skills inside government, as well as new systems for obtaining and sharing information.

This latter point broaches the theme of 'open government', which is different from engagement as a co-creating activity and, rather, involves sharing data so that outsiders can create value in often surprising ways (e.g., Kettl's example of Baltimore's Rat Rub-out, Queensland's use of social media to deal with emergencies and volunteers, and New Zealand's use of Twitter and Facebook to inform citizens of tax consultations). Like social media more generally, leaders in government have to prepare bureaucracies to better anticipate, see possibilities, and develop a degree of comfort with how such data and technology can be used.

\section{What capabilities need to be developed in government to better respond to and anticipate citizen demands for better services and engagement?}

This volume offers insights about the capabilities required for dealing with citizens and communities, either directly or indirectly. What follows distils and clusters these observations under several themes:

\section{Aligning government capabilities for a citizen focus}

- Develop an internal vision and new staff mind-sets first.

- Find and assign committed and visionary leaders to accomplish goals.

- Don't rely solely on a few leaders: build teams and supporting capabilities.

- Build internal structures and systems first to support critical external tasks.

- Keep executives and ministers informed.

- Build collaborative capabilities and expertise with other organisations.

\section{Developing new perspectives on possibilities}

- Use diverse ways to build perspective and develop 'professional empathy'.

- Engage diverse citizen representatives and different kinds of experts; look broadly.

- Ensure that staff are familiar with citizen and community needs.

- Develop comprehensive perspectives on service chains and environments.

- Share findings and validate information. 
Putting Citizens First

\section{Managing discovery, change and engagement processes}

- Develop a long view on the engagement/change process.

- Identify multiple channels for feedback and engagement, including social media.

- Consult on how best to engage given citizen needs and preferences.

- Sustained listening is critical for problem-solving and delivery solutions.

- Seek feedback and data on the performance of your organisation.

- Genuine co-creation requires sharing decisions, not securing endorsement.

- Act like a 'junior partner' in networks and communities.

- Don't try to convert networks and partnerships into service arms.

- Be prepared to work and respond in new ways.

- Develop priorities, and focus energy in promising, fundamental areas.

- Removing impediments is as important as finding new ways to work.

- Don't promise what can't be delivered; follow through with commitments.

\section{Reporting and accountability}

- Build accountability into the engagement process.

- Regularly report on progress to stakeholders, executives, ministers.

- Identify different phases of transformation/engagement; consider exit plans.

This list is not meant to serve as a 'one-size-fits-all' checklist that should be applied in all efforts to engage, work with, and serve citizens and communities. But it does summarise a good deal of the wisdom that is contained in this collection, albeit from very diverse and specific cases. Parallel to Stoker's opening observations, it is important to have a broad perspective and repertoires on how to engage and serve citizens, and then to carefully identify the right mix for the tasks and circumstances at hand. Nor should the list be seen as more competencies to be piled onto those already expected of front-line staff, middle managers, and executives across government. Rather, it points to the qualities governments should seek in a critical subset of leaders and staff who can make big difference — with the right support — by influencing much larger groups of people inside and outside government when engaging citizens.

This latter point should mollify the concerns of some observers (see Podger 2012), who worry about whether the sensibility advocated by 'putting citizens first' could lead to excessive focus on responding to citizen needs and providing tailored service at the expense of government priorities and budget constraints in our Westminster system. While the vertical accountability structure and often closed decision-making processes associated with cabinet governance can hamper more aggressive efforts to engage and respond to citizens, and 
recognising that successive duly elected governments will have distinct priorities, the cases reviewed from Australia, New Zealand and other countries show that experimentation and progress on 'putting citizens first' can proceed in very different governance contexts.

Finally, while the list above points to building capability for specific initiatives independently in departments and agencies, capability should also be developed across departments and agencies, and even across governments. There are so many potential approaches for engaging with citizens and for better understanding their needs and those of communities, it may be difficult for even the biggest departments to keep up with emerging approaches. The recent announcement of the Centre for Excellence in Public Sector Design, an 18-month pilot funded by the Australian Public Service Secretaries Board for the Commonwealth government and located at The Australian National University, is a promising sign. A similar capability could be developed for different approaches to engaging citizens, since Australian and New Zealand universities are repositories of world-class expertise in this area.

\section{References}

Advisory Group on the Reform of Australian Government Administration. 2010. Ahead of the Game: Blueprint for the reform of Australian Governmentadministration. Canberra: Commonwealth of Australia.

Alford, J. 1998. 'A Public Management Road Less Travelled: Clients as coproducers of public services', Australian Journal of Public Administration, v. 57:4 (December), pp. 128-37.

- 2009. Engaging Public Sector Clients: From service-delivery to co-production. Palgrave Macmillan.

Alford, J. and O'Flynn J. 2009. 'Making Sense of Public Value: Concepts, critiques and emergent meaning', International Journal of Public Administration, v. 32, pp. 171-91.

- and - 2012. Rethinking Public Service Delivery: Managing with external providers. Palgrave.

Australia, Government 2.0 Task Force. 2009. Engage: Getting on with Government 2.0, Report of the Government 2.0 Task Force (22 December). Canberra: Commonwealth of Australia.

Bason, Christian. 2010. Leading Public Sector Innovation: Co-creating for a better society. Policy Press. 
Bingham, L.B., Nabatchi, T. and O'Leary, R. 2005. 'The New Governance: Practices and processes for stakeholder and citizen participation in the work of government', Public Administration Review, v. 65:5 (September/October), pp. 547-58.

Borins, S., Kernaghan, K., Brown, D., Bontis, N., Perri 6 and Thompson, F., (eds). 2007. The Digital State: At the leading edge. Toronto: University of Toronto Press.

Bovaird, T. 2007. 'Beyond Engagement and Participation: User and community coproduction of public services', Public Administration Review (September/ October), pp. 846-60.

Boyle, D., and Harris, M. 2009. The Challenge of Co-production: How equal partnerships between professionals and the public are crucial to improving public services, Discussion Paper (December). London: New Economics Foundation.

Christensen, T. and Laegreid, P., eds. 2002. The New Public Management: The transformation of ideas and practice. Burlington, Vermont: Ashgate.

- and - eds. 2007. Transcending New Public Management: The transformation of public sector reforms (Burlington, Vermont: Ashgate, 2007).

Dinsdale, G. and Marson D.B. 1999. Citizen/Client Surveys: Dispelling myths and redrawing maps. Ottawa: Canadian Centre for Management Development. Available at www.csps-efpc.gc.ca/pbp/pub/pdfs/P90_e.pdf.

Dutil, P., Howard, C.. Langford, J. and Roy, J. 2010. The Service State: Rhetoric, reality and promise. University of Ottawa Press.

Dunleavy, P., Margetts, H., Bastow, S. and Tinkler, J. 2006. 'New Public Management is Dead: Long live digital-era governance', Journal of PublicAdministration Research and Theory, v. 16:3, pp. 467-94.

Economic Audit Committee. 2009. Putting the Public First: Partnering with the community and business to deliver outcomes. Perth: State of Western Australia.

Halligan, J. and Wells, J. 2008. The Centrelink Experiment: Innovation in service delivery. Canberra: ANU E Press. Available at: epress.anu.edu.au/anzsog/ centrelink/pdf/prelims.pdf.

Heintzman, R. and Marson, B. 2005. 'People, Service and Trust: Is there a public sector value chain?', International Review of Administrative Sciences, v. 71:4, pp. 549-75. 
Hendriks, Carolyn M. 2012. 'Participatory and collaborative governance', in Rodney Smith, Ariadne Vroman and Ian Cook (eds), Contemporary Politics in Australia: Theories, practices and issues. Cambridge University Press.

Howard, C. 2010. 'Are we being served? A critical perspective on Canada's Citizens First satisfaction surveys', International Review of Administrative Sciences, v 76:1, pp. 65-83.

John, P., Cotterill, S., Richardson, L., Moseley, A., Smith, G., Stoker, G. and Wales, C. 2011. Nudge, Nudge, Think, Think: Using experiments to change civic behaviour. London: Bloomsbury Academic.

Kernaghan, K. 2005. 'Moving Toward the Virtual State: Integrating services and service channels for citizen-centred service', International Review of Administrative Sciences, v. 71:1, pp. 119-31.

- 2009. 'Moving Towards Integrated Public Governance: Improving service delivery through community engagement'. International Review of Administrative Sciences, v. 75:2, pp. 239-54.

Lindquist, E. 2010. 'From Rhetoric to Blueprint: The Moran Review as concerted, comprehensive and emergent strategy for public service reform', Australian Journal of Public Administration, v. 69:2 (June), pp. 115-51.

Marson, B. and Heintzman, R. 2009. From Research to Results: A decade of results-based service improvement in Canada. Toronto: Institute of Public Administration of Canada. Available at: www.ipac.ca/documents/ NewHorizonsmarsonandheintzman.pdf.

Matheson, A. and Szwarc, D. 2008. Public Sector Service Value Chain: Linking employee engagement and customer satisfaction. Victoria: BC Stats. Available at: www.bcstats.gov.bc.ca/data/ssa/reports/WES/WES2008EmployeeCustomerLink.pdf.

Moore, Mark H. 1995. Creating Public Value: Strategic management in government. Harvard University Press.

OECD. 2001. Citizens as Partners: OECD handbook on information, consultation and public participation. Paris.

—. 2009. Focus on Citizens: Public engagement for better policy and services. Paris.

- 2011. The Call for Innovative and Open Government: An overview of country initiatives. Paris. 
Podger, A. 2012. 'Putting Citizens First: A priority that needs to be addressed with care', Australian Journal of Public Administration, v. 71:1 (March), pp. 85-90.

Smith, G. 2005. Beyond the Ballot: 57 democratic innovations from around the world. London: The Power Inquiry.

Schmidt, F. and Strickland, T. 1998a. Client Satisfaction Surveying: Common Measurements Tool. Ottawa: Canadian Centre for Management Development. Available at www.gov.mb.ca/stem/stm/pdfs/CCSN_CMT.pdf.

— and - 1998b. Client Satisfaction Surveying: A manager's guide. Ottawa: Canadian Centre for Management Development. Available at www.gov. mb.ca/stem/stm/pdfs/CCSN_CMT.pdf.

Roy, J. 2008. 'Beyond Westminster Governance: Bringing politics and public service into the networked era', Canadian Public Administration, v. 51:4 (December), pp. 541-68.

Wanna, J., Butcher, J. and Freyens, B. 2010. Policy in Action: The challenge of service delivery. Sydney: University of New South Wales Press. 